MIDPI sciforum
MOL2NET, International Conference Series on Multidisciplinary Sciences http://sciforum.net/conference/mol2net-03

\title{
Antioxidant activity of 5-FU and new fluorinated uracil derivates
}

C. Casanova (E-mail) ${ }^{\mathrm{a}}$, ML. Moreno (ml.moreno@ucv.es) ${ }^{\mathrm{b}}$, M. Miranda (mmiranda@uchceu.es) ${ }^{\mathrm{a}}$, I. Almansa A (ialmansa@uchceu.es) $)^{\mathrm{a}}$, Falcó (afalco@uchceu.es) ${ }^{\mathrm{a}}$, A. Navarro (angeles.navarro@ucv.es) ${ }^{\mathrm{b}}$ S. Fustero (santos.fustero@uv.es) ${ }^{c, d}$, S. Mérida (salvador.merida@uchceu.es) $)^{\mathrm{a}}$,VM. Villar (vmvillar@uchceu.es) ${ }^{\mathrm{a}}$

${ }^{a}$ Department of Biomedical Sciences, Universidad Cardenal Herrera-CEU, CEU Universities, Alfara del Patriarca, Valencia, Spain

${ }^{b}$ Department of Basic Sciences, Universidad Católica de Valencia “San Vicente Mártir”, Torrente, Valencia, Spain

${ }^{c}$ Laboratory of Organic Molecule, Department of Organic Chemistry, Facultad de Farmacia, Universitat de València, Burjassot, Valencia, Spain

${ }^{d}$ Príncipe Felipe Research Centre, Valencia, Valencia, Spain

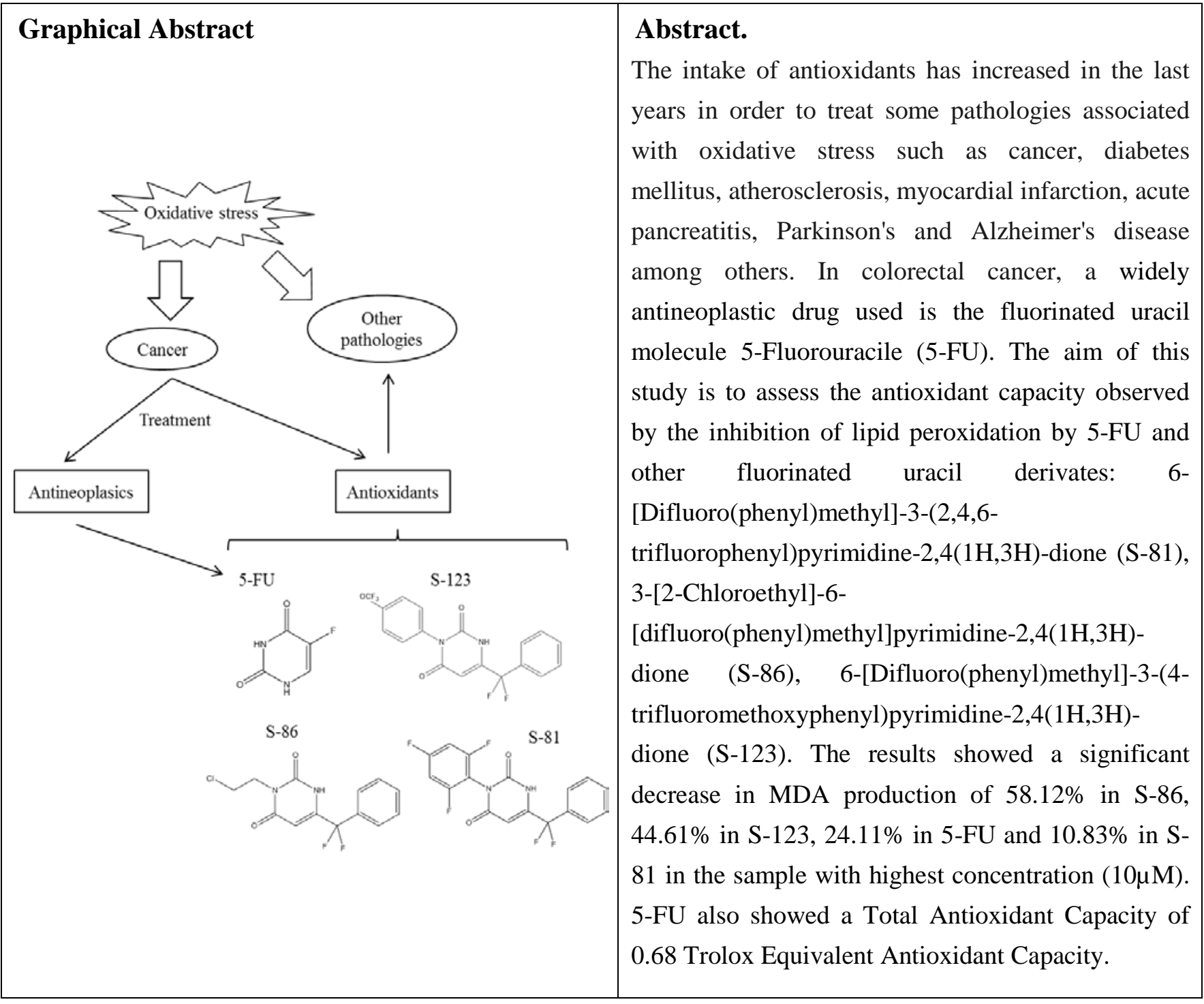




\section{References}

Serero A., J. Lopes A. Nicolas and S. Boiteux (2008). "Yeast genes involved in cadmium tolerance: Identification of DNA replication as a target of cadmium toxicity." DNA Repair (Amst) 7(8): 12621275.

Surekha R.H., Srikanth B.B, Jharna P, Ramachandra R.V., Dayasagar R.V. and Jyothy A. (2007)

Oxidative stress and total antioxidant status in myocardial infarction. Singapore Med J. 48: 137-142.

Nereis: https://www.ucv.es/investigacion/publicaciones/catalogoderevistas/revistanereis 